\title{
Representasi Pribumi dalam Iklan \\ Surat Kabar Pandji Poestaka 1940-1941
}

\author{
Noveri Faikar Urfan \\ Alumnus Program Studi Ilmu Komunikasi UII Yogyakarta; \\ Mahasiswa S2 Ilmu Komunikasi UGM Yogyakarta
}

\begin{abstract}
Pandji Poestaka is a newspaper founded by the Netherland Indies colonial government, that is Commisie voor de Volkslectuur (Commission of the People Reading), or better known as Balai Poestaka. This study attempts to examine how the representation of natives in the colonial period in Pandji Poestaka ads 1940-1941. Using semiotics, this study shows that Pandji Poestaka ads has presented natives representation in the dichotomous class stratification. The native aristocracy (priyayi) and the underprivileged (wong cilik). Priyayi look represented the image of modernity: educated, wealthy, and civilized. Meanwhile, wong cilik has been overwritten by inferior image representation: traditional, blue-collar workers, and lazy. These representations, seen as part of the colonial strategy to maintain its position in the Netherland Indies. By representing social class among the natives, colonialism tried to keep the gap class. Colonialism also took advantage of the mass media (Pandji Poestaka) as an ideological state apparatus to continue, maintain power, and institutionalize the ideology of colonial rule.
\end{abstract}

Keywords: Pandji Poestaka, native, representation, class inequality, colonial ideology.

\begin{abstract}
Abstrak
Pandji Poestaka adalah surat kabar yang didirikan oleh Pemerintah Kolonial Hindia Belanda, yaitu Commisie voor de Volkslectuur (Commision of the People Reading), dikenal lebih luas sebagai Balai Poestaka. Kajian ini mencoba menjelaskan bagaimana representasi pribumi selama masa penjajahan dalam iklan Pandji Poestaka tahun 1940-1941. Menggunakan analisis semiotika, kajian ini menunjukkan bahwa iklan di Pandji Poestaka merepresentasikan dikotomi stratifikasi kelas: para aristokrat (priyayi) dan rakyat jelata (wong cilik). Priyayi direpresentasikan memiliki semua citra modernitas: berpendidikan, kaya raya, dan beradab. Sementara wong cilik digambarkan sebagai kelompok inferior: tradisional, pekerja kerah biru, dan pemalas. Representasi ini, dilihat sebagai bagian dari strategi penjajah untuk mempertahankan posisinya di Hindia Belanda. Dengan merepresentasikan kelas sosial para pribumi, penjajah mencoba untuk merawat kesenjangan kelas. Para penjajah juga memanfaatkan Pandji Poestaka sebagai alat ideologis untuk melanjutkan, mengelola kekuasaan, dan melakukan institusionalisasi ideologi dan peraturan-peraturan kolonial.
\end{abstract}

Kata Kunci: Pandji Poestaka, pribumi, representasi, kesenjangan kelas, idiologi kolonial. 


\section{Pendahuluan}

Pada masa kolonialisme Hindia-Belanda banyak iklan-iklan di berbagai terbitan media massa, yang secara tak langsung telah mengundang persepsi tentang inferioritas pribumi. Contohnya, iklan Shell Waterwitte Petroleum, dalam koran Sin Po, 19 Juli 1923 (Riyanto dalam Susanto, 2003: 51). Dalam iklan ini digambarkan seorang pribumi dengan pakaian lurik ala Madura, dengan mata terbelalak dan kaget karena ia hampir tidak bisa membedakan antara air dan minyak bahan bakar, "wa!.. saya kira itu ajer", begitu bunyi headline iklan itu.

Di luar fungsi iklan sebagai sarana pemasaran, entah dengan maksud yang disengaja atau tidak, tampilan visual iklan itu telah menggiring pembacanya pada ruang imaji tertentu tentang masyarakat pribumi. Bukan lain adalah gambaran tentang mereka yang naif dan terbelakang, yang belum mampu membedakan mana air dan mana minyak.

Tidak berlebihan jika dikatakan bahwa iklan di masa Hindia-Belanda, telah menjadi salah satu bagian dari strategi kolonial dalam membentuk persepsi tentang pribumi. Persepsi itu dengan sengaja dibentuk melalui pencitraan yang mengarah pada dua sisi rasial yang saling berseberangan. Pribumi selalu dicitrakan sebagai masyarakat tradisional, irasional, naif, dan terbelakang. Sedangkan bangsa kolonial akan menempati citra yang menurut mereka telah mewakili dirinya, yakni rasional, beradab dan lebih maju.

Melihat persoalan di atas, agaknya menarik untuk membahas bagaimana iklan di masa kolonialisme HindiaBelanda telah menjadi bagian dari strategi kolonial dalam mewacanakan pribumi. Mengingat iklan adalah salah satu sarana komunikasi yang sangat strategis untuk menghadirkan berbagai persepsi, terutama tentang bangsa kolonial yang superior dan berhak memerintah, dan pribumi yang inferior dan harus menerima kepemimpinan moral maupun politik bangsa kolonial.

Dalam persoalan inilah, penulis tertarik untuk melakukan kajian tentang bagaimana masyarakat pribumi direpresentasikan dan diwacanakan dalam iklan surat kabar pada masa penjajahan Hindia-Belanda. Objek kajian yang dipilih adalah iklan surat kabar Pandji Poestaka yang terbit pada tahun 1940-1942. Surat kabar Pandji Poestaka sengaja dipilih karena kedekatannya dengan kepentingan kolonialisme di Hindia Belanda.

Pandji Poestaka sebenarnya adalah terbitan yang dikeluarkan oleh Commisie voor de Volkslectuur (Komisi Bacaan Rakyat), sebuah badan penerbitan yang didirikan oleh pemerintah kolonial pada tahun 1908, yang kemudian lazim disebut dengan nama Balai Poestaka (Lombard, 2008: 192). Pada masanya, Balai Poestaka adalah penerbit yang menghasilkan banyak bahan bacaan, serta 
berkembang dan menghasilkan banyak sastrawan yang berpengaruh dalam perkembangan sastra Indonesia modern, seperti H. B. Jassin, Marah Roesli, dan Sutan Takdir Alisjahbana.

Pada awal kemunculannya, Balai Poestaka didirikan untuk membendung menjamurnya berbagai penerbitan yang tak terkendali waktu itu. Balai Poestaka menjadi penerbit penyedia bahan bacaan resmi yang diakui oleh pemerintah kolonial. Penerbit ini sekaligus menjadi sarana politik etis guna menumbuhkan kegemaran membaca dan memajukan pengetahuan pribumi sesuai dengan kemajuan zaman (Pradopo, 2002: 101103).

Terlepas dari maksud itu, kehadiran Balai Poestaka tidak bisa dilepaskan dari kepentingan pemerintah kolonial. Kepentingan pemerintah kolonial itu, salah satunya terwujud dalam penetapan aturan umum yang ketat pada terbitan Balai Poestaka. Pemerintah kolonial memberi aturan bahwa bacaanbacaan terbitan Balai Poestaka tidak boleh sampai berbau politik, apalagi merusak kewibawaan pemerintahan kolonial (Teeuw, 1995: 57-60). Selain itu, penerbit ini juga selalu berusaha menyebarkan suatu ideologi ortodoks yang secara implisit menguntungkan orang Eropa.

Di luar terbitan berupa buku-buku bacaan dan karya sastra, Balai Poestaka juga menerbitkan surat kabar, yaitu Sri Poestaka (bulanan, sejak 1919) dan Pandji
Poestaka (mingguan, sejak 1922). Tidak jauh berbeda dengan bacaan-bacaan lain, surat kabar ini juga tak lepas dari kepentingan pemerintah kolonial dan dikenai aturan pokok yaitu tidak boleh merusak kewibaan pemerintah kolonial.

Dalam surat kabar inilah tampilan visual iklan banyak ditemukan, iklan-iklan itu banyak menawarkan berbagai nacam produk komersial yang mulai menjamur seiring berjalannya proses industrialisasi di Hindia-Belanda. Melajunya proses industrialisasi ini, ditandai dengan pesatnya laju produksi barang dan jasa, yang pada gilirannya membutuhkan jasa iklan sebagau sarana komunikasi pemasaran untuk menjangkau konsumen secara luas.

Selain tujuannya sebagai sarana komunikasi pemasaran, iklan juga bisa dikatakan sebagai sebuah artefak budaya yang memberikan gambaran tentang semangat dan persoalan pada zamannya (Riyanto dalam Susanto, 2003: 22). Sebab itu, mengkaji iklan juga membutuhkan pengetahuan yang mendalam tentang konteks zaman dan keadaan ketika teks iklan itu dihadirkan. Pengetahuan tentang konteks ini berguna untuk memberi gambaran tentang teks itu secara lebih utuh, lengkap dengan macam-macam persoalan yang melingkari kehadiran teks iklan itu sendiri.

Selanjutnya, iklan juga punya arti penting di mana kemunculannya telah memancing hadirnya persoalan tentang 
representasi. Representasi menjadi isu yang menarik, sebab di dalamnya identitas-identitas dihadirkan dan dilibatkan di tengah berbagai kepentingan, bahkan relasi kekuasaan yang ikut melatarbelakangi proses kehadiran tersebut. Sebagai hasilnya representasi bisa menghadirkan gambaran tentang siapa yang dominan dan siapa yang terpinggirkan, serta wacana apa saja yang ikut mempengaruhinya (Hartley, 2010: 66-67).

Persoalan representasi dalam iklan di masa Hindia-Belanda akhirnya menjadi penting untuk dikaji secara serius, mengingat identitas masyarakat pribumi telah dipertaruhkan pada ajang kepentingan kekuasaan kolonial waktu itu. Pribumi banyak diwacanakan sebagai sosok yang lemah dan tak berdaya di bawah bayang-bayang represif praktik kolonialisme. Sebab itulah diperlukan pembacaan yang kritis dan mendalam guna membongkar wacana-wacana dalam iklan di masa kolonial, yang notabene telah menyudutkan kaum pribumi dalam ruang imajinasi yang inferior.

Studi ini akan menjawab dua pertanyaan: pertama, bagaimana representasi pribumi Indonesia di Masa Kolonial dalam iklan surat kabar Pandji Poestaka terbitan 1940-1941; dan kedua, bagaimana nilai-nilai tersembunyi (mitos/ideologi) dalam iklan surat kabar Pandji Poestaka?

\section{Metode Penelitian}

Dalam penelitian ini, penulis menggunakan metode analisis semiotika, dengan mengombinasikan perangkat analisis dari tokoh semiotika Ferdinand de Saussure, Roland Barthes, dan ahli antropologi struktural Claude Levi Strauss. Dari pemikiran Saussure, analisis semiotika akan disandarkan pada kerangka analisis sintagma, yakni hubungan kehadiran (in presentia) untuk memperoleh makna sebenarnya dalam iklan (Budiman, 2011: 27-28). Setelah melakukan analisis sintagma, analisis semiotika akan dilanjutkan dengan mengetengahkan aspek paradigmatik, yakni hubungan ketidakhadiran (in absentia), untuk dikaitkan dengan konotasi-konotasi sehingga akan berhubungan dengan adanya mitos (ideologi) seperti yang diketengahkan oleh Roland Barthes.

Oleh karena objek kajian penelitian ini adalah iklan, maka objek kajian ini akan diperlakukan dengan mengangkat dimensi-dimensi khusus di dalamnya. Dalam analisis sintagma, iklan dalam penelitian ini akan dianalisis berdasarkan empat dimensi yang ada dalam iklan itu sendiri, yakni anchorage (penambat), argument (proposisi), montage (tata panorama), dan narrative (penceritaan) (Tolson, 1996: 28-43).

Setelah melakukan analisis sintagma, makna-makna sebenarnya dalam iklan yang diteliti, kemudian akan 
ditempatkan dalam hubungan paradigmatik untuk dikaitkan dengan konotasi-konotasi. Proses hubungan konotasi tersebut, berikutnya akan membawa teks iklan yang diteliti pada hubungannya dengan mitos (ideologi). Dalam melakukan analisis mitos, penelitian ini akan terbantu oleh penggunaan perangkat kategorisasi oposisi biner (binary opposition) yang diperkenalkan oleh Claude Levi Strauss.
Sistem oposisi biner nantinya akan sangat berguna untuk menemukan struktur dan pemahaman yang tepat dalam memahami mitos pada objek penelitian (iklan Pandji Poestaka). Setelah menguraikan mitos dalam struktur oposisi biner, selanjutnya akan diterangkan pula bagaimana mitos tersebut bermain, atau dikonstruksi secara historis yang melibatkan berbagai pengetahuan, kepentingan dan tentunya ideologi.

\section{Iklan-Iklan Pandji Poestaka 1940-1941}

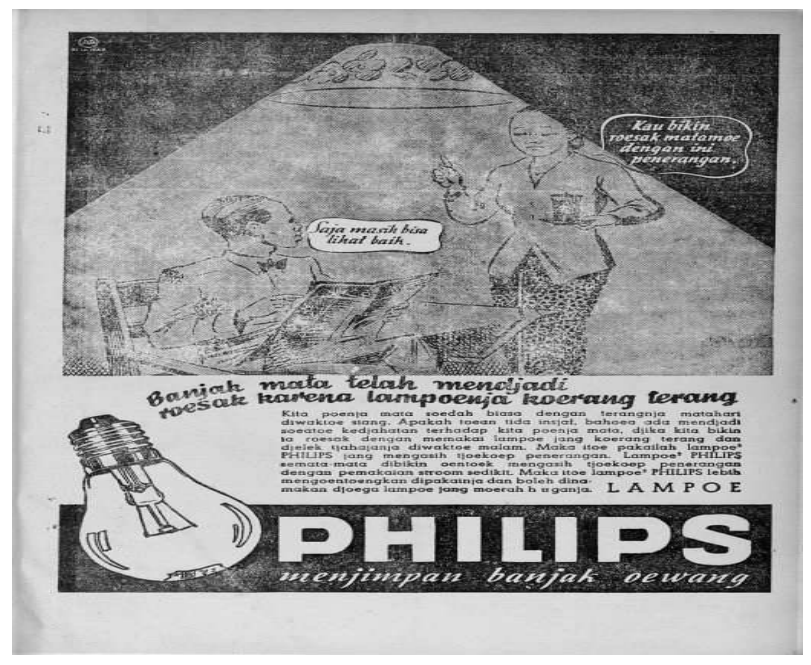

Gambar 1. Lampu Philips, 6 Januari 1940

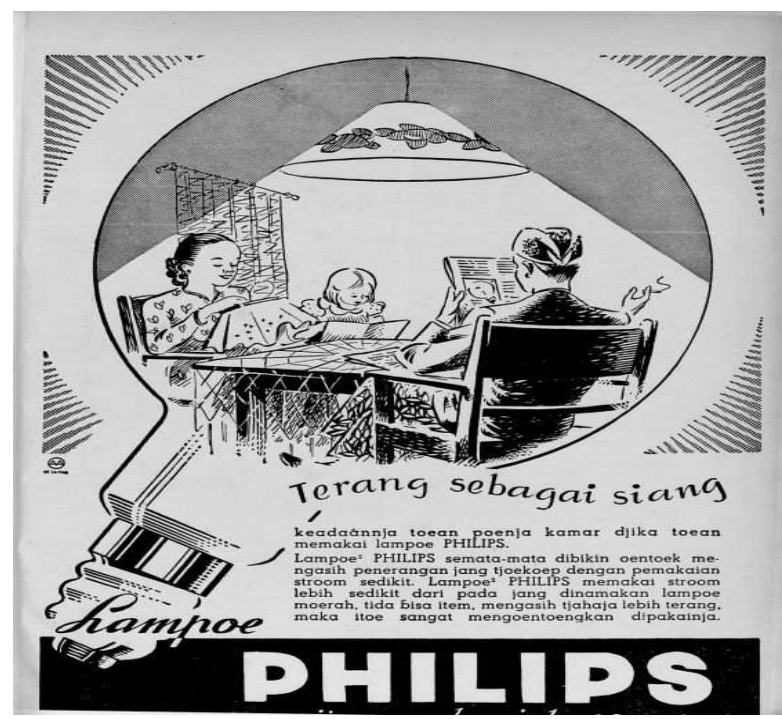

Gambar 2. Lampu Philips, 3 Februari 1940 


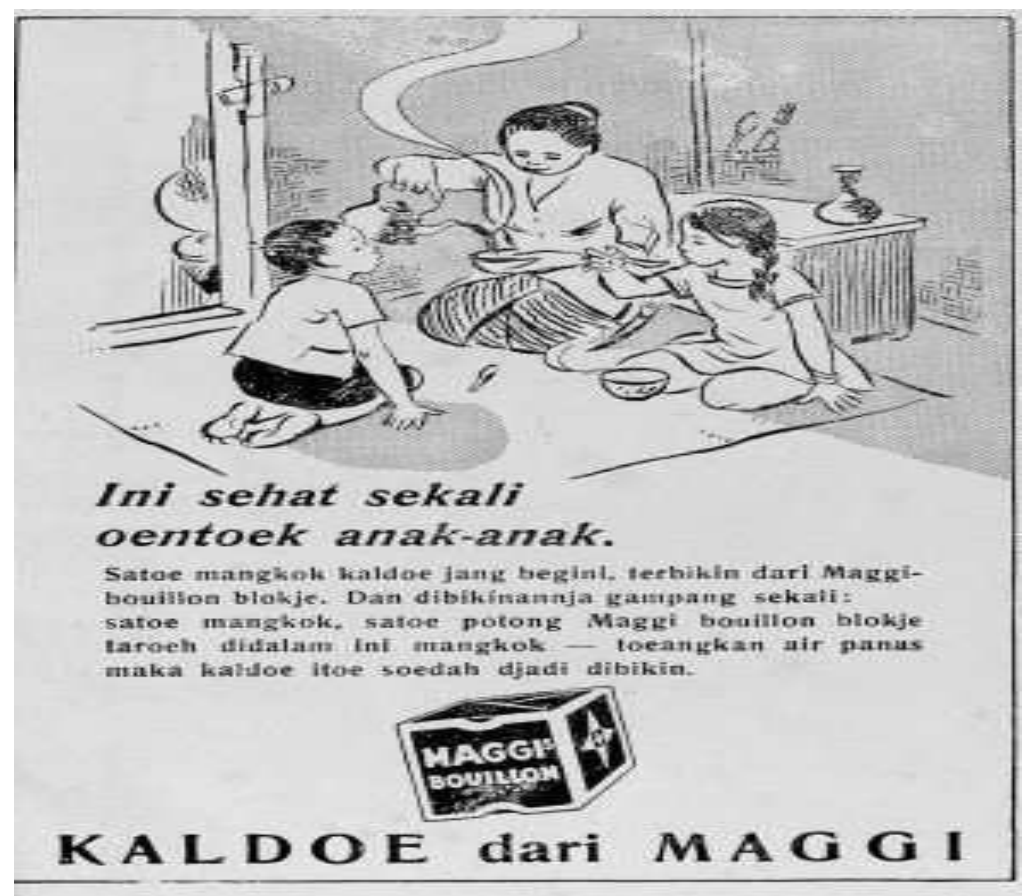

Gambar 3. Kaldu Maggi Bouillon, 24 Januari 1940

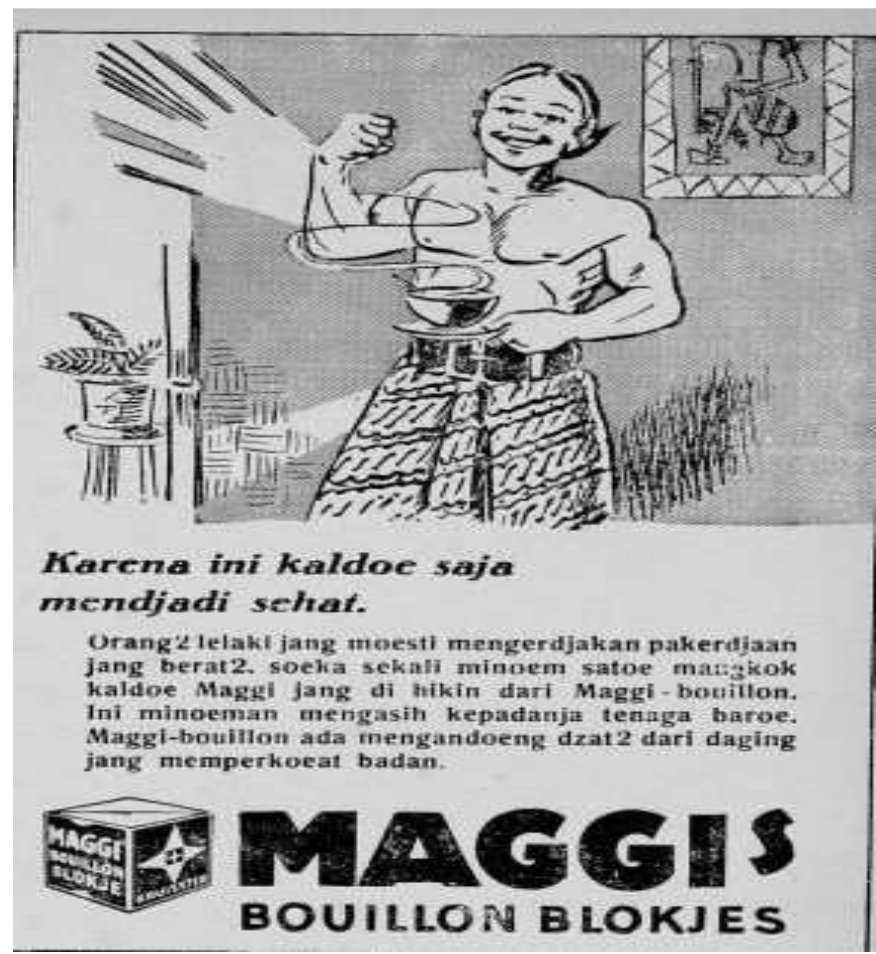

Gambar 4. Iklan Maggi Bouillon, 24 Februari 1940 


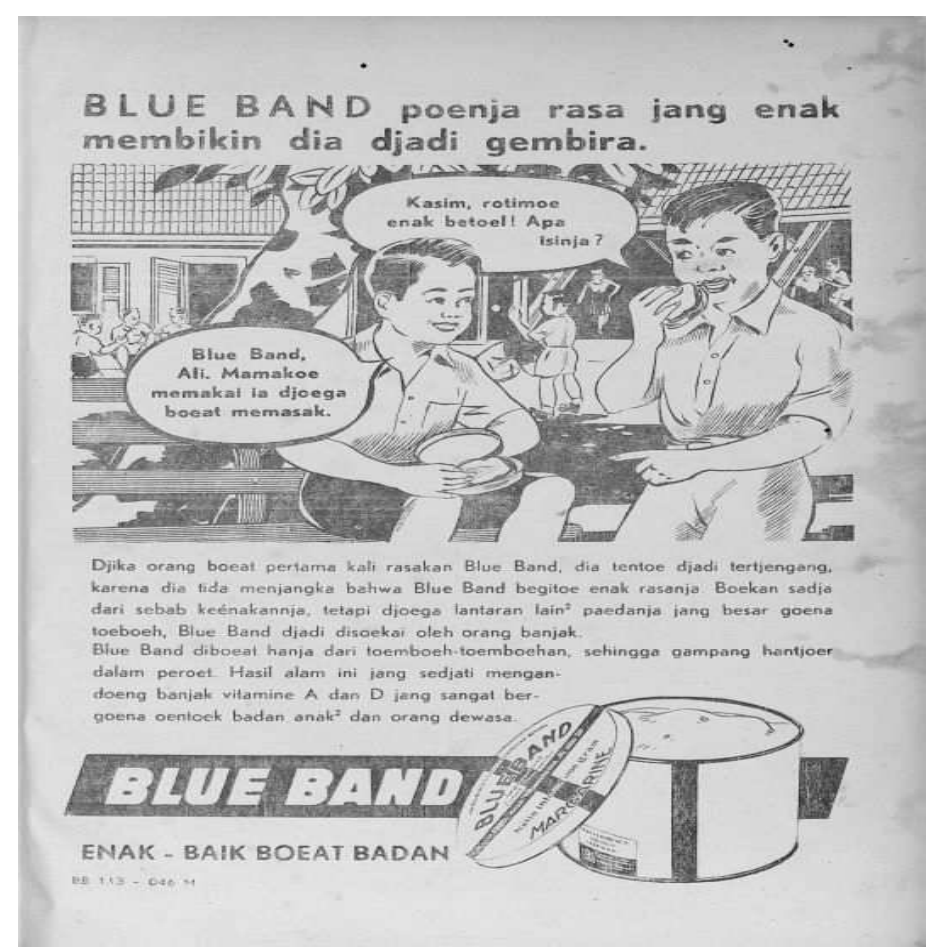

Gambar 5. Blue Band Margarine 15 Oktober 1941

\section{Konotasi Iklan}

\section{Tabel Konotasi}

\begin{tabular}{lll}
\hline No & \multicolumn{1}{c}{ Jenis Iklan } & \multicolumn{1}{c}{ Konotasi yang Muncul } \\
\hline 1 & Lampu Philips & $\begin{array}{l}\text { Orang Jawa. Pencerahan. Pengetahuan. } \\
\text { Modernisasi” }\end{array}$ \\
2 & Kaldu Maggi & $\begin{array}{l}\text { Orang Jawa. Bahan instan. Tradisional. } \\
\text { Pekerja kasar. }\end{array}$ \\
3 & Blue Band Margarine & Pribumi. Berpendidikan. Industrialisasi \\
\hline
\end{tabular}




\section{Mitos Iklan Pandji Poestaka}

Untuk mempermudah terlihatnya temuan dalam penelitian semiotika ini, penggunaan model oposisi biner Levi Strauss dalam menyimpulkan mitos, akan membantu penulis untuk menemukan bagaimana representasi atas pribumi dalam iklan Pandji Poestaka.

Relasi oposisisi biner dalam mitos Iklan Pandji Poestaka adalah sebagai berikut:

\section{Skema mitos pribumi dalam iklan Pandji Poestaka}

$\begin{array}{ll}\text { Kolonial } & : \text { Pribumi } \\ \text { Pribumi priyayi } & : \text { Pribumi jelata } \\ \text { Modern } & : \text { Tradisional } \\ \text { Beradab } & : \text { Belum Beradab } \\ \text { Kaya } & : \text { Miskin } \\ \text { Elit } & : \text { Pekerja Kasar } \\ \text { Rajin } & : \text { Malas } \\ \text { Pintar } & : \text { Bodoh }\end{array}$

Dalam skema ini, tampak jelas bahwa iklan Pandji Poestaka telah merepresentasikan pribumi dalam kategori oposisi kelas dengan sifat-sifat yang dikotomik. Iklan Pandji Poestaka merepresentasikan pribumi priayi sebagai masyarakat yang telah modern, beradab, kaya, elit, dan pintar. Sedangkan pribumi jelata direpresentasikan secara oposisif sebagai tradisional, tidak beradab, miskin, pekerja kasar, dan bodoh.

Citra atas priyayi pribumi yang modern, beradab, kaya, dan seterusnya, kiranya cukup kuat direpresentasikan oleh iklan Pandji Poestaka, khususnya dalam iklan lampu Philips dan Blue Band. Dalam dua iklan ini, sangatlah terlihat bahwa pribumi telah bersanding dengan berbagai macam atribut elit dan modern (pada zamannya) seperti lampu listrik, koran, sekolah.

Sementara itu, pribumi jelata dicitrakan secara berkebalikan dari pribumi priyayi. Pribumi jelata dengan sifat-sifat: tradisional, belum beradab, miskin, bodoh dan pekerja kasar, kiranya cukup kuat direpresentasiakn oleh iklan kaldu Maggi Bouillon, di mana dalam iklan ini atribut-atribut tradisionalitas banyak muncul, seperti dinding anyaman bambu, alat masak tradisional, dan sosok pria pekerja.

Dalam hubungan kelas yang dikotomis ini, iklan Pandji Poestaka boleh dikatakan telah memanfaatkan jurang kelas sosial di kalangan pribumi untuk memasarkan produk-produknya. Untuk memasarkan produk-produk elit seperti lampu dan mentega pelapis roti, iklan Pandji Poestaka memanfaatkan figur sosok priyayi yang modern dan terdidik. Sementara dalam memasarkan produk sederhana, seperti kaldu, iklan Pandji Poestaka memanfaatkan figur pribumi jelata dengan tampilan sosok yang dilingkupi atribut-atribut tradisional seperti tikar, anyaman bambu dan alatalat masak tradisional. 
Representasi Kesenjangan Kelas di Masa Hindia Belanda

Setelah menguraikan secara singkat oposisi biner di atas, dalam menjelaskan mitos pribumi, alangkah baiknya jika penulis akan mendudukkan juga bagaimana persoalan dikotomi kelas yang muncul dari representasi iklan surat kabar Pandji Poestaka ke dalam dua konteks yang agaknya tepat dan relevan. Konteks pertama adalah bagaimana wacana kolonialisme beroperasi, sedangkan konteks kedua adalah relevansi historis tentang kesenjangan kelas di masa Hindia Belanda. Penjelasan ini, agaknya akan berguna untuk memberi dukungan atas skema mitos di atas, agar ketepatannya bisa terjustifikasi dalam konteks yang tepat dan relevan.

Dalam kajian kritis seputar wacana kolonialisme, misalnya seperti yang diungkapkan oleh Ania Loomba, kolonialisme tidak cukup hanya didudukkan dalam persoalan perebutan paksa- aset-aset produksi dan pelanggaran hak asasi secara fisik. Akan tetapi, seperti yang diungkapkan pula oleh Edward Said, bahwa kolonialisme juga bergerak dalam diskursus tentang pemaksaan klaim di mana masyarakat terjajah selalu ditempatkan dalam kategori "liyan" yang inferior di bawah superioritas kaum kolonial (Gandhi, 1998: 101-102).

Ketika berbicara konteks kolonialisme di Hindia Belanda, maka persoalan kelas sosial di mana pribumi sendiri dianggap sebagai "liyan" dalam kategori kolonial, maka upaya melihat persoalan ini harus pula didudukkan secara diskursif terkait bagaimana pemaksaan klaim "inferior", ditindihkan secara semena-mena oleh kolonial kepada pribumi.

Pada awal abad 19 misalnya, Dennys Lombard (2008: 154-155) mencatat bahwa ungkapan "kemalasan pribumi" sudah menjadi pendapat umum di Hindia Belanda, melalui istilah-istilah: luij (malas), ijverloosheijt (ketidaktekunan pribumi). Belum lagi sebutan-sebutan umum yang terdengar diskriminatif pada kaum pekerja kasar pribumi dengan panggilan baboe (pengasuh), coeli (tukang angkut), atau djongos (pembantu rumah tangga). Stereotip diskriminatif ini, pada dasarnya menguatkan pandangan bahwa dalam praktik kolonialisme di Hindia Belanda, masyarakat pribumi hampir selalu ditempatkan dalam bingkai rasial yang diskriminatif.

Selain Lombard, Syaid Hussein Alatas, pun dalam tulisannya "The Mith of the Lazy Native", mengungkapkan bagaimana mitos atau stereotip "malas" yang ditancapkan oleh kolonial kepada pribumi. Dennys Lombard menegaskan hal serupa, mitos kemalasan tersebut pada dasarnya didasari oleh penetrasi kepentingan ekonomi Hindia Belanda sejak abad 19 dengan meluasnya perkebunan dan pemanfaatan kaum 
pribumi sebagai tenaga kerja (Lombard, 2008: 154).

Jika diingat kembali pada gambargambar dalam iklan Pandji Poestaka, khususnya pada iklan kaldu Maggi Bouillon, agaknya akan tampak citra atas inferioritas pribumi dalam iklan tersebut. Di mana atribut-atribut yang berdekatan dengan konotasi tentang tradisionalitas dan kemiskinan jamak ditemui, seperti perabot masak tradisional, anyaman bambu (gedhek), dan tikar. Hal ini tampak makin menguatkan kecurigaan bahwa iklan Pandji Poestaka telah ikut mewacanakan bahwa pribumi adalah kaum lemah dan inferior.

Sejak diterapkannya sistem politik etis pada awal abad 20, arus modernisasi terus menguat di Hindia Belanda. Sejak saat itu, barang-barang produksi modern, seperti mesin-mesin produksi, mobil, kereta api, lampu listrik, dan berbagai barang dan jasa modern kian bermunculan. Akan tetapi, akses kepada barang-barang modern tersebut, tampaknya hanya bisa dinikmati oleh segelintir elit (golongan Eropa dan Priyayi) sebagai pemegang tahta kelas tertinggi di masyarakat. Jika diingat kembali pada iklan Pandji Poestaka dalam penelitian ini, contohnya adalah iklan Lampu Philips, agaknya kesenjangan akses pada barang produksi modern tersebut akan tampak cukup jelas.

Lampu listrik sendiri, di masa Hindia Belanda adalah barang elit yang tidak sembarang orang bisa menikmatinya, sebab listrik pada waktu itu hanya dipasok secara terbatas. Data di tahun 1930 menunjukkan bahwa di Jawa dan Madura terdapat Sembilan juta rumah, 50.00o di antaranya dihuni oleh orang Eropa, sementara perusahaanperusahaan listrik memasok 200.000 jaringan listrik, yang tentu sebagian besar masuk ke kantong-kantong rumah elit Eropa, priyayi, kantor, hotel, perusahaan, fasilitas umum dan sebagainya (Maier dalam Nordholt, 1997: 85).

Dari pemaparan ini, tampak jelas bahwa lampu listrik sebagai barang industri modern hanyalah dinikmati dan diakses oleh segelintir orang yang memiliki kedudukan elit. Tidak hanya Philips, barang-barang modern produksi Belanda juga ikut meramikan konsumsi kaum elit, seperti minuman bermerk Ovomaltine, pasta gigi Colgate, margarin Palmboon dan Blue band (Maier dalam Nordholt, 1997: 85). Barang-barang produksi modern ini juga bisa dipandang sebagai atribut sosial yang meneguhkan keunggulan status sosial pemakainya. Sebab ekslusivitas akses pada barangbarang industri tersebut pada kalangan elit, adalah bukti bahwa kesenjangan kelas di masa Hindia Belanda begitu kentara.

Tidak hanya itu, dalam akses pendidikan di masa Hindia Belanda, pertimbangan atas stratifikasi kelas sosial sangatlah berpengaruh. Pendidikan (sekolah) pada masa Hindia Belanda umumnya hanya diakses secara terbatas 
oleh kalangan elit pribumi (priyayi) dan Eropa. Apabila diingat kembali tentang tanda-tanda dalam iklan Pandji Poestaka seperti iklan Philips di mana terdapat gambaran seorang pembaca surat kabar dan di iklan Blue Band yang terdapat siswa sekolah, sebenarnya hal ini adalah representasi dari elitisme pendidikan waktu itu yang hanya dinikmati oleh segelintir kelompok elit.

Data dari sensus penduduk di tahun 1930 menunjukkan bahwa di Jawa hanya terdapat $6 \%$ penduduk yang bisa membaca dan menulis, dan tidak ada alasan signifikan yang menguatkan adanya jumlah peningkatan sampai saat iklan Philips dan Blue Band di surat kabar Pandji Poestaka 1940-1941 terbit (Maier dalam Nordholt, 1997: 94-95). Rendahnya tingkat melek huruf di Hindia Belanda ini, sebenarnya diakibatkan oleh kebijakan pemerintah kolonial yang diskriminatif dan cenderung memelihara kesenjangan kelas.

Pendidikan pada masa itu, boleh dikata adalah bagian dari strategi pemerintah Hindia Belanda untuk meningkatkan jumlah pekerja administratif bagi birokrasi kolonial (Sutherland, 1983: 13). Daripada pemerintah mendatangkan tenaga ahli dari Belanda, akan lebih efisien jika masyarakat pribumi diberi akses bersekolah agar bisa diarahkan sebagai pekerja administrasi di bawah pemerintah kolonial. Upaya ini juga sekaligus sebagai visi jangka panjang pemerintah kolonial untuk mendudukkan Hindia di bawah pemerintahan Belanda dengan sistem pemerintahan tidak langsung (indirect rule), di mana administrasi pribumi di Hindia akan dikelola oleh korps kepegawaian pribumi (Inlandsche Bineland Bestuur) di bawah komando pemerintahan kolonial Belanda.

Dalam rangka upaya inilah, kemudian pemerintah kolonial Hindia Belanda membuka akses pendidikan bagi golongan pribumi. Akan tetapi, dalam praktiknya, pendidikan di Hindia Belanda masih sangat diskriminatif, di mana dari golongan pribumi hanya golongan elit priyayi yang dekat dengan pemerintah kolonial saja yang kemudian berhasil mendapatkan akses pendidikan waktu itu, sementara rakyat jelata tetap saja dipinggirkan (Riyanto dalam Susanto, 2003: 32). Pada akhirnya, hal ini juga makin memperpanjang rantai diskriminasi kelas sosial di masa itu, di mana kesenjangan antara kaum elit dengan rakyat jelata terlihat sangat jelas.

Bila kita coba menengok kembali iklan-iklan yang ditampilkan dalam surat kabar Pandji Poestaka dalam penelitian ini, di mana pada dasarnya terdapat citra yang dikotomis antara kelas sosial rakyat jelata (dalam iklan kaldu Maggi) dan priyayi (iklan Blue Band dan Philips), maka bisa dikatakan bahwa iklan tersebut sebenarnya turut merepresentasikan adanya kesenjangan kelas sosial di masa 
itu. Agaknya, iklan Pandji Poestaka tidaklah cukup ditempatkan hanya sebagai saluran komunikasi pemasaran barang, akan tetapi iklan tersebut juga ikut memelihara kesenjangan kelas pada zamannya. Ini sangat tampak dari persoalan akses barang industri modern dan pendidikan; akses istimewa selalu berada di tangan para elit (Eropa dan priyayi), sementara rakyat jelata selalu ditempatkan dalam kategori inferior dan tidak berdaya.

Dalam konteks seperti ini, iklan di masa kolonial tampaknya tak sekedar berfungsi dalam aras utama sebagai praktik komunikasi pemasaran barang dan jasa. Akan tetapi, ia pun menjadi agen ideologis untuk mempertahankan kesenjangan kelas agar kekuasaan kolonial terjaga. Realitas ini agaknya bisa dijelaskan dengan memakai pandangan seorang kritikus Karl Marx, yakni Louis Althusser. Dalam pandangannya, Althusser menganggap bahwa pandanganpandangan determinisme ekonomis dalam marxisme klasik, sudah tidak memadai lagi untuk menjelaskan persoalan kelas yang kian kompleks (Harland, 2006: 71).

Sebab, persoalan ketidakadilan kelas tidak lagi cukup dijelaskan dengan hanya menganggapnya dalam konteks relasi pekerja dan pemilik modal. Akan tetapi, bagaimana kapitalisme beroprasi dan mempertahankan kesenjangan kelas, telah didukung oleh adanya superstruktur yang mengamankan keberlangsungan moda produksi dan cara-cara kapitalisme mempertahankan

kekuasaan. Superstruktur atau lembaga ini, disebut oleh Althusser (1992: 50-53) sebagai ideological state apparatus (aparat ideologis negara), yang difungsikan sebagai agen struktural untuk memelihara dan melegitimasi dominasi ideologis.

Aparat ideologis tersebut, contohnya adalah: lembaga represif seperti kepolisian, militer, penjara, persidangan. Sedangkan lembaga ideologis adalah sekolah, institusi agama, media massa, budaya populer dan sebagainya. Althusser memandang bahwa relasi ketidakadilan yang disebabkan oleh cara-cara produksi telah diamankan oleh superstruktur dari aparatus represif dan aparatus ideologis. Melalui aparatus represif kekuasaan dipelihara melalui cara-cara paksaan, sementara dengan aparatus ideologis, kekuasaan dipelihara secara halus (Strinati, 2007: 172).

Berdasarkan perspektif ini, agaknya persoalan relasi antara iklan, kelas dan ideologi kolonial bisa dijelaskan. Iklan surat kabar Pandji Poestaka adalah aparatus ideologi negara, sebab Pandji Poestaka memang didirikan oleh pemerintah Hindia Belanda sendiri. Melalui iklan Pandji Poestaka sebagai aparat ideologi negara, kekuasaan kolonial kemudian coba terus dikukuhkan dengan representasi perbedaan kelas-kelas sosial. Dengan menempatkan media massa sebagai aparatus negara, pemerintah kolonial mempunyai posisi tawar yang 
kuat untuk mempengaruhi cara pandang massa secara ideologis.

$$
\text { Dengan terus menerus }
$$

merepresentasikan priyayi sebagai modern, terdidik, dan seterusnya, di saat bersamaan pula, citra tentang tradisionalitas dan kemiskinan ditindihkan kepada rakyat jelata, dengan begitu kolonialisme menjaga kesenjangan kelas di Hindia Belanda. Kesenjangan kelas ini, begitu menguntungkan kolonial, sebab mereka telah menduduki hirarki kelas tertinggi bersama kalangan elit-elit lokal (priyayi). Dengan begitu, kolonialisme tetap bertahan sebab kedudukan tinggi dalam kelas sosial akhirnya berbanding lurus dengan kepemilikan aset-aset produksi, sehingga motif ekonomi kapitalisme tetap berjalan.

Akhirnya, begitulah kesenjangan kelas sosial di masa kolonial dipertahankan melalui praktik represntasi. Iklan kolonial merepresentasikan priyayi yang dekat dengan kolonial sebagai modern dan terdidik, sedang pada saat bersamaan, wong cilik dicitrakan sebagai kaum yang hidup dalam hirarki kelas terbawah, tradisional, dan miskin.

\section{Penutup}

Analisis semiotika atas representasi pribumi dalam iklan Pandji Poestaka 1940-1941, memperlihatkan dua citra dikotomis, yakni citra pribumi priyayi dan pribumi jelata (wong cilik).
Representasi tentang priyayi muncul dari iklan-iklan berjenis kebutuhan elit (pada zaman itu), seperti lampu listrik dan makanan kaleng Blue Band Margarine. Sementara representasi wong cilikatau rakyat jelata ditemukan dalam iklan kaldu dengan kemasan sederhana.

Pribumi direpresentasikan oleh iklan Pandji Poestaka dalam kategori kelas sosial yang dikotomis. Pribumi priyayi yang terkenal dekat dengan pemerintah kolonial dicitrakan sebagai golongan modern, elit, terdidik, sementara golongan wong cilik atau rakyat jelata direpresentasikan dengan citra-citra tradisional dan pekerja kasar dan miskin.

Praktik representasi ini, bisa dipandang sebagai strategi kolonial dalam mempertahankan pengaruh dan kedudukannya sebagai penguasa Hindia Belanda. Dengan merepresentasikan kelas sosial di kalangan pribumi, kolonialisme berusaha menjaga kesenjangan kelas tersebut. Kesenjangan kelas terus menguntungkan bangsa kolonial, sebab mereka telah menduduki hirarki tertinggi dalam kelas sosial bersama golongan elit priayi.

Pemerintah kolonial Hindia Belanda tampak memanfaatkan media massa sebagai aparatus ideologi negara. Di mana media massa surat kabar Pandji Poestaka (iklan) dimanfaatkan untuk terus menjaga dan melembagakan cara pandang massa terhadap pandangan kelas. Melalui iklan tersebut, citra priyayi 
yang dekat dengan kolonial terus dijaga dengan merepresentasikan mereka dengan citra modern, terdidik, kaya, sementara wong cilik terus dipinggirkan dalam citra-citra tradisional, miskin, dan pekerja kasar.

Eksploitasi terhadap wong cilik, berjalan beriringan dengan praktik representasi melalui media massa (Pandji Poestaka). Hal ini berguna untuk menutupi adanya kebobrokan atau pelanggaran kemanusiaan yang telah dilakukan oleh pemerintah kolonial Hindia Belanda dengan adanya eksploitasi, kerja paksa, serta berbagai bentuk pelanggaran hak asasi manusia selama kolonialisme dijalankan.

\section{Daftar Pustaka}

Barthes, Roland. 1972. Mithologies. (Trans: Annette Lavers). London: Granada Publishing.

Barthes, Roland. 2010. Membedah MitosMitos Budaya Massa. (Terj: Ikramullah Mahyuddin).

Yogyakarta: Jalasutra.

Budiman, Kris. 2011. Semiotika Visual, Konsep, Isu, dan Problem Ikonisitas, Yogyakarta: Jalasutra.

Easthope, Antony \& Kate McGowan. 1992.

A Cultural and Cultural Theory Reader. Buckingham: Open University Press.
Gandhi, Leela. 1998. Postcolonial Theory: A Critical Introduction. Edinburgh: Edinburgh University Press.

Gouda, Frances. 2007. Dutch Culture Overseas: Praktik Kolonial di Hindia Belanda, 1900-1942. (Terj: J. Soegiarto \& Suma R. Rusdiarti). Jakarta: Serambi Ilmu Semesta.

Harland, 2006. Superstrukturalisme. (Terj: Iwan Hernawan). Yogyakarta: Jalasutra.

Hartley, John. 2010. Communication, Cultural \& Media Studies: Konsep Kunci. (Terj: Kartika Wijayanti). Yogyakarta: Jalasutra.

Kartodirjo, Sartono. 1987. Perkembangan Peradaban Priyayi. Yogyakarta: UGM Press.

Loomba, Ania. 2003. Kolonialisme/Pascakolonialisme.

(Terj: Hartono Hadikusumo). Yogyakarta: Bentang.

Lombard, Dennys. 2008. Nusa Jawa Silang Budaya 1: Batas-Batas Pembaratan . Jakarta: Gramedia.

Lombard, Dennys. 2008. Nusa Jawa Silang Budaya II: Jaringan Asia. Jakarta: Gramedia.

Nordholt, Henk Schulte (ed). 1997. Outward Appearences: Dressing State and Society in Indonesia. Leiden: KITLV Press. 
Pandji Poestaka 1940-1941. Terarsip di http://niod.xcago.com/maleise_kranten/papers. do. Akses 23 Maret 2012.

Pradopo, Rachmat Djoko. 2002. Kritik Sastra Indonesia Modern. Yogyakarta: Gama Media.

Riyanto, Bedjo. 2000. Iklan dan Perubahan Massyarakat di Jawa Masa Kolonial (1870-1915). Yogyakarta: Tarawang.

Rohman, Mujibur. 2010. Wacana Kolonial dan Kritik Poskolonialisme. Jurnal Sosiologi Reflektif: Vol 4, No 2. April 2010.

Samuel, Hanneman. 2010. Genealogi Kekuasaan Ilmu Sosial Indonesia, Dari Kolonialisme Belanda hingga Modernisme Amerika. Jakarta: Kepik Ungu.

Strinati, Dominique. 2007. Popular Culture: Pengantar Menuju Teori Budaya Polpuler. (Terj: Abdul Mukhid). Yogyakarta: Penerbit Jejak.
Sutherland, Heather. 1983. Terbentuknya Sebuah Elit Birokrasi. (Terj: Sunarto). Jakarta: Sinar Harapan.

Susanto, Budhi Sj (ed). 2003. Identitas dan Postkolonialitas di Indonesia. Yogyakarta: Kanisius.

Teeuw, A. 1995. Pokok dan Tokoh dalam Kesustraan Indonesia Baru. Jilid 1. Cetakan ke 3. Jakarta, Pembangunan.

Tolson, Andew. 1996. Mediation Text and Discourse in Media Studies. London: Arnold. 
Jurnal komunikasi, Volume 6, Nomor 2, April 2012 